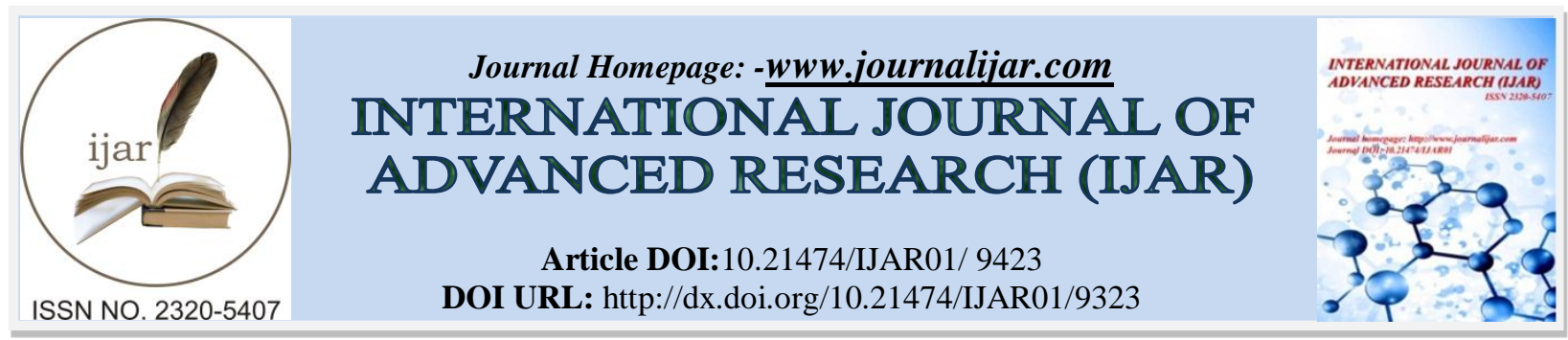

RESEARCH ARTICLE

\title{
IMPACT OF WEATHER ON RICE PRODUCTION IN INDIA.
}

\author{
Saumya Verma. \\ PhD Scholar, Department of Economics, Delhi School of Economics, University of Delhi, New Delhi - 110017, \\ India.
}

\section{Manuscript Info}

Manuscript History

Received: 22 May 2019

Final Accepted: 24 June 2019

Published: July 2019

Key words:-

agriculture, India, production function, rainfall, rice, temperature.

\begin{abstract}
In India, agriculture is the core sector of our economy. In this study, I estimate the impact of weather variables on mean and variance of yields of rice - at the district level using a large panel dataset from 1966-1999. Rice is a temperature sensitive crop. Moreover, it also requires sufficient amount of rainfall for production. Results show that higher temperature adversely affects variance of rice yields. Higher rainfall, on the other hand, reduces yield variability of rice. A degree Celsius increase in temperature is expected to increase rice yield variability by 20 percent, where as an additional $100 \mathrm{~mm}$ of rainfall reduces yield variability by 1 percent.
\end{abstract}

Copy Right, IJAR, 2019,. All rights reserved.

\section{Introduction:-}

Significant warming of the Earth's surface and ocean temperatures over the past century has been attributed to anthropogenic activities (IPCC 2007). For India, annual mean temperature has increased gradually but continuously over 1901-2007, along with accelerated warming in recent years (Kothawale et al. 2010). Simulation results from global and regional climate models for India predict a significant increase in annual mean temperature and summer monsoon rainfall, along with significant inter annual variability in both, which will manifest in increased intensity, high frequency extreme events in the 2030's (GoI 2010).

In India, agriculture alone (excluding forestry and fisheries) accounts for 12 percent of Gross Domestic Product (GDP) and is a major source of livelihood for around 69 percent of the rural population (GoI 2011). According to an Indian Planning Commission Report, around 80 percent of the poor reside in rural areas (GoI 2013), and depend on agriculture for their sustenance.

The present study looks at the effect of weather variables (in addition to other inputs) on agricultural production in India. In this study, I focus on rice, which is a major foodgrain grown in India.

Rice is the staple crop of Asia and is central to the food security of about half of the world's population (FAO 2013), The crop accounts for approximately 30 percent of the total dietary intake, globally and in South Asia (Lobell et al. 2008). India accounts for approximately 67 percent of total rice production in South Asia. The crop accounts for 23.3 percent of gross cropped area and about 43 percent of total food grain production in India (Singh 2009). Rice production in the tropics is sensitive to climatic factors (temperature, rainfall, and solar radiation) which affect the crop in various ways during different stages of its growth (Yoshida 1981). The Green Revolution, which took place in the 1960's led to a substantial increase in rice and wheat production. Production of millets has more or less

Corresponding Author:-Saumya Verma.

Address:-PhD Scholar, Department of Economics, Delhi School of Economics, University of Delhi, 777 
remained constant between1966-2006 whereas that of rice and wheat has increased by 125 percent and 285 percent, respectively (MNI 2009).

The present study examines the impact of climate change on mean and variance of yields of rice. The analysis is conducted with district-level data from 1966 to 1999, the period for which continuous data is available at the district level. Changes in weather are found to affect crop yield levels and variances in a crop specific fashion. Higher rainfall increases mean yield of rice, indicating that rice requires high rainfall for production. Increases in temperature increase rice yield variability, where as higher rainfall reduces yield variability.

The paper is organized as follows. In the next section, the role of weather variables in agricultural production is discussed, followed by growing pattern of rice. Section 3 describes related literature. Section 4 provides a description of the data and methodology. Section 5 presents the estimation procedure. Section 6 describes the results. Section 7 concludes the paper.

\section{Trends in weather variables}

India's climate system is dominated by the summer or south-west monsoon (and to a lesser extent by the winter or North-east monsoon). South West monsoon rainfall is a major source of precipitation for India and parts of South Asia (Ramanathan et al. 2005) and accounts for over 80 percent of India's rainfall (Bagla 2012). Owing to the monsoon's pivotal role in the Indian economy in general, it is one of the most studied weather phenomena. Agricultural production depends crucially not only on the amount of rainfall, but its distribution across space and time (Goswami et al. 2006). Studies point to a gradual and accelerated weakening of the Indian monsoon, with increased frequency and intensity of rainfall extremes (Auffhammer et al. 2012).

Studies have found decreasing trends in early and late monsoon rainfall and number of rainy days for India from 1951-2003, followed by a significant expansion of total area with monsoon rainfall one standard deviation below the mean (Ramesh and Goswami 2007). ${ }^{1}$ Studies based on Greenhouse Gas forced model based scenarios of the IPCC also indicate intensification of rainfall in most parts of India except for central and north east India (May 2004). More recently, Krishnamurthy (2012) studied frequency and intensity of rainfall extremes in India using non parametric trend analysis and finds a rising trend in rainfall extremes in the coastal and eastern regions respectively.

Rising trends in annual mean temperature coupled with an increased heat wave frequency since the middle of the $20^{\text {th }}$ century have been observed in many parts of Asia. Results of the Coupled Model Inter Comparison Project Phase 5 (CMIP5) simulations for the Representative Concentration Pathway (RCP) scenarios predict a warming of $2{ }^{\circ} \mathrm{C}$ in the mid $21^{\text {st }}$ century, with warming exceeding $3^{\circ} \mathrm{C}$ for South and South East Asia to more than $6^{\circ} \mathrm{C}$ for high latitude regions (IPCC 2014). Regarding temperature trends for India, mean annual temperature shows a significant warming trend of $0.51^{\circ} \mathrm{C}$ per 100 years during the period 1901-2007 (Kothawale et al. 2010). More importantly, accelerated warming has been observed in the last forty years (1971-2007), due to intense warming in the recent decade (1998-2007). Increases in mean temperature have been accompanied by a rise in both maximum and minimum temperatures -- by 0.71 and $0.27^{\circ} \mathrm{C}$, respectively, per hundred years during the period 1901-2007. At a regional level, homogeneous regions of East coast, West coast and the peninsula show an increasing trend in the frequency of hot days but Northern India does not. On the contrary, all regions show a decreasing trend in the frequency of cold days (GoI 2010). Dash et al. (2007) examine regional and seasonal trends in rainfall and temperature for seven zones, namely, north west, western Himalaya, north Central, north east, interior peninsula, east coast and west coast from 1901-2003. They find a significant increase in maximum temperature across all regions of India, with the highest being $1.2^{\circ} \mathrm{C}$ for the West Coast and lowest being $0.5^{\circ} \mathrm{C}$ in the Interior Peninsula. Further, increase in minimum temperature is found to be the most for the Interior Peninsula, with the least being $0.2^{\circ} \mathrm{C}$ for the West Coast. Post monsoon (October to December) and monsoon (June to September) months experience significant warming.

Growing pattern and climatic requirements of rice

Rice is cultivated throughout the country. Its production is highly sensitive to natural calamities. The Green Revolution has led to a significant improvement in rice productivity in Asia through a combination of new high-

\footnotetext{
${ }^{1}$ Similar results are reported in Pattanaik (2007), who found decreasing trend in monsoon rainfall over northwest and central India for the period 1941-2002.
} 
yielding varieties with increased input use, such as stable water supply from new irrigation systems, fertilizer, and biocide use (Hossain and Fischer, 1995). HYV seeds were adopted in many of the rainfed ecosystems of India as well. Expansion of tubewell irrigation was responsible for higher production in eastern Uttar Pradesh and West Bengal (Barah 2005).

Rice is a water intensive crop and is grown under rain fed conditions and / or irrigation. Cumulative rainfall required for growth is 1200-1300 mm. Drought stress is the largest constraint to rice production affecting 10 million hectares of upland rice and over 13 million hectares of rainfed lowland rice in Asia alone (Pandey et al. 2007). The 2002 drought, affected 55 percent of the land area and around 300 million people, lead to a 20 percent decline in rice production from the inter annual baseline trend (Pandey et al. 2007). Further, the likelihood of a drought in consequent years affects farmer's investment decisions, which affects future agricultural productivity.

Depending on the depth of standing water in the fields, rainfed rice area has been further classified into upland and lowland rice area. Upland rice area accounts for 14 percent of the all India rice area and includes the states of Assam, Bihar, (east) Madhya Pradesh, Orissa, (east) Uttar Pradesh, West Bengal and hilly region of the North East. However, productivity of upland rice is rather low, with an average yield of 0.90 tonnes per hectare, which is less than the all India rice productivity of 1.90 tonnes per hectare. Upland rice production is characterised by no standing water in the fields after rain. Lowland rice area in India is around 14 million hectares, and accounts for 32 percent of the total rice area. Low land rice production is however, characterised poor soil quality and experiences drought/flood conditions resulting in higher variability in production. Low land rice area is further divided into shallow water, semi deep water and deep water rice area, where area with depth of (standing) water in the fields of less than $50 \mathrm{~cm}$ is considered shallow, with 50-100 cm semi deep and exceeding $100 \mathrm{~cm}$ is considered as deep water. However, the crop is also grown under irrigation in the states of Punjab, Haryana, Uttar Pradesh, Jammu and Kashmir, Andhra Pradesh, Tamil Nadu, Sikkim, Karnataka, Himachal Pradesh and Gujarat (GoI 2014).

In India, rice is grown in three seasons, namely, autumn (pre-kharif), winter (kharif) and summer (rabi), where these seasons have been named according to the season of harvest. Winter or kharif rice (sown during June-July and harvested in November-December) is the main growing season and accounts for 84 percent of total rice production currently. Medium and long duration varieties of rice are grown during this season (GoI 2014). This is followed by summer rice (sown during November-February and harvested in March-June) at 9 percent and autumn rice (sown during May-August and harvested in September-October) which accounts for 7 percent of rice production ${ }^{2}$.Early maturing varieties are grown during summer season, where as short duration varieties are mainly grown during autumn (GoI 2014). The sowing and harvesting period however, varies across states, depending on rainfall patterns, temperature, land quality, and availability of other agricultural inputs. However, it is grown throughout the year in southern and eastern states such as Andhra Pradesh, Karnataka, Kerala, Orissa and Assam (ICAR 2008). Further, the crop is grown mainly under irrigation in the states of Punjab, Haryana, Uttar Pradesh, Jammu and Kashmir, Andhra Pradesh, Tamil Nadu, Sikkim, Karnataka, Himachal Pradesh and Gujarat (GoI, 2014). Punjab and Haryana account for close to 11 percent of the all India rice production, but have emerged as major producers in recent years, owing to extensive use of HYV seeds coupled with use of irrigation water to meet crop input requirements.

Among the three growth phases, namely, vegetative, reproductive and ripening phase, water stress during the reproductive stage affects rice production the most, with effects as severe as premature abortion of the seed in addition to depressing grain formation (Saini and Westgate 2000). Rice is a thermal sensitive crop, with temperatures suitable for growth varying by growth phase of the crop. During June-September day temperatures upto $35^{\circ} \mathrm{C}$ and night temperatures upto $25^{\circ} \mathrm{C}$ are suitable for rice growth (Wassman et al. 2009). High temperature affects cellular and developmental processes leading to reduced fertility and grain quality (Barnabas et al. 2008). Decreased grain weight, reduced grain filling, higher percentage of white chalky rice and milky white rice are common effects of high temperature exposure during the ripening phase (Yoshida et al. 1981). Studies based on General Circulation Models and SRES (Special Report on Emission scenarios) scenarios show that higher temperatures reduce rice yields significantly (IPCC 2014).

In addition to weather inputs, rice production is input intensive and requires organic and inorganic fertilizers for growth. Upland rice cultivation requires sufficient organic manure which increases water holding capacity of the soil. However, the amount of fertilizer used depends on soil fertility and existing climatic conditions (GoI, 2014).

${ }^{2}$ This discussion is based on Singh (2009). 


\section{Literature Review}

Several studies have analysed the economic impact of climate related variables on crop yields for India. District level panel datasets for India have been used in several studies like Dinar et al. (1998), Sanghi and Mendelsohn (2008), Guiteras (2009) and recently by Krishnamurthy (2012).

The first four use the Ricardian approach which estimates the impact of climate variables on net agricultural revenues per unit area. Coefficient estimates obtained from these studies are however, not reliable as they suffer from omitted variable bias, which the panel data analysis conducted in this paper accounts for. Cross sectional regressions of this type ignore significant information in the data by averaging both, the dependent and independent variables

Deschenes and Greenstone (2007) use a variant of the Ricardian approach and estimate the impact of variation in climate variables on US annual agricultural profits and find that climate change will increase annual profits by 4 percent. Among the more recent studies Guiteras (2009) examines the impact of temperature and rainfall on combined yield of six major crops in India ${ }^{3}$ which account for 75 percent of total revenue. The precipitation variable has been defined both as total monthly rainfall (for growing seasons months i.e. June - September) as well as total growing season rainfall. He finds that climate change could reduce yields by 4.5 percent to 9 percent in the medium run (2010-2039) and by as much as 25 percent in the long run (2070-2099) in the absence of long run adaptation. The main drawback of this study as highlighted by Krishnamurthy (2012) is of combining crops which differ significantly from each other (in terms of input requirements, growing season etc) to arrive at a monetary measure with ill defined prices. Fishman (2012) use district level data for India from 1970-2004 to estimate climate change impacts, inter alia on crop yields. Rainfall distribution during the monsoon months is captured by the frequency of rainy days (i.e. days with precipitation more than $0.1 \mathrm{~mm}$, May 2004), and shape parameter of the gamma distribution, which is a measure of skewness of the rainfall distribution and finds that expansion of irrigation can help mitigate adverse effects of higher rainfall variability. Kumar et al. (2014) estimate the effect of climate variables on average rice yields in India, and find higher maximum temperatures to be reducing rice yields. Using a state level panel data set for India, Kumar et al (2014) finds significant adverse effects of maximum temperature, minimum temperature and changing rainfall pattern on crop yields in India.

However, few studies have estimated climate change impacts on yield variance in developing economies. Cabas et al. (2010) examine the effect of climate and non climate factors on mean and variance of corn, soybean and winter wheat yield in Canada from 1981-2006.Variation in climate is captured by the coefficient of variation (CV) for temperature and rainfall, where CV captures the effects of extreme events. However, their analysis is based on a limited number of counties. Higher temperature and precipitation variability is found to reduce average crop yields and increase crop yield variability.

Mc Carl et al. (2008) on the basis of their study for corn, soybean and sorghum yields for the United States conclude that precipitation intensity and extent of rainfall deficiency are important determinants of crop yields. Their analysis is based on a state level panel data set for US states from 1960-2007. Apart from annual precipitation, precipitation intensity and Palmer Drought Severity Index has been used to capture rainfall intensity and severity of a wet or dry spell respectively. They find that precipitation intensity and droughts are important predictors of crop yields than the total amount of precipitation. Temperature variability is captured by the standard deviation of temperature, which is found to reduce yields of all crops. Increased precipitation intensity increases sorghum yield variability.

Kumar et al (2015) estimate the impact of climate and non climate variables on mean yield and yield variability of sugarcane yields in India (as in this study). Analogous to Cabas et al (2010) coefficient of variation was used to capture inter annual seasonal variation in maximum temperature, minimum temperature and rainfall, in addition to other non climate inputs. Higher temperature adversely affects crop yields, with both higher maximum temperature during summer and minimum temperature during winter reducing average yields. Higher variability in minimum temperature reduces average yields. Higher maximum temperature during winter and minimum temperature during summer increases yield variability. Higher rainfall during winter season increases yield variability. However, most of the climate variables do not explain yield variability significantly.

\footnotetext{
${ }^{3}$ The six crops are rice, wheat, jowar, bajra, maize and sugarcane.
} 
Boubacar (2012) examine the impact of climatic fluctuations on mean yields and yield variability of maize, millet and sorghum using data for 8 counties of Sahel from 1970-2000. Climate extremes are found to increase yield variability.

One such study for India, which uses the three step Feasible Generalized Least Squares Procedure (as in this study) to estimate the Stochastic Production Function, is by Barnwal and Kotani (2010), where the effect of temperature and precipitation on mean and variance of seasonal crop yields is studied for Andhra Pradesh for the time period 1969-2002. Standard deviation of climate variables (over months) are included as separate regressors to capture intra seasonal variance of the climate variables. Climate change impacts are allowed to vary across agro climatic zones by including interaction terms of climate variables with a dummy for that agro climatic zone as separate regressors. Higher intra seasonal variance of rainfall and temperature is found to reduce mean yields and increase yield variability across agro climatic zones. A similar study by Poudel and Kotani (2013), find a one to one relation between climate variability and crop yield variability across agro climatic zones in Nepal. They also capture heterogeneity in climate impacts across altitudes by separate dummies for low, middle and high altitude regions. Hasanthika et al (2013) use a district level panel of 6 major rice growing districts in Sri Lanka from 1980-2010, and find climate variables to augment production risk. Edeh et al (2011) use time series data on crop yields and climate variables for Ebonyi in Nigeria from 2000-06 and find that rainfall variations are a major cause of uncertainty in crop production in Africa. Higher growing season temperature increases crop yield variability; higher intensity reduces variability, where as higher relative humidity makes yields more variable.

Using a panel data set of 26 provinces in China from 1985-2007, Holst et al. (2011) investigate the impact of several climatic and non climatic inputs on mean aggregate output (which in turn comprises quantities of different varieties of rice, wheat, corn, sorghum, millet, tubers and beans) and output variability. Deviation in precipitation from the long period average increase risk for the southern provinces, in support of the fact that rainfall is a crucial input for agricultural production and deviations in rainfall affect the crop adversely. Sarker (2014) use both, three step FGLS procedure and MLE to analyse the impacts of rainfall and temperature on crop yields in Bangladesh. The impact of climate variables on average yields and variance vary in a crop specific fashion, and results are specific to the functional form used. Increases in temperature are shown to increase production risk in crop production.

However, one of the major limitations of these studies is that they do not account for agricultural inputs used in agricultural production. Cabas et al (2010) include input change as a regressor, which measures the aggregate inputs used. However, there is no mention of the exact set of inputs included in this variable. Another state level study by Auffhammer et al (2006) accounts for the use of irrigation, fertiliser and high yielding variety seeds. However, district level studies do not account for these inputs, which affect production in addition to weather. In this study, I analyse variability in climate while controlling for the major inputs used by the farmers, namely, irrigated water, HYV seeds and fertilizers.

\section{Data and Methodology:- \\ Data}

\section{Agricultural Data}

Data on agricultural variables for 311 districts of India from 1966-1999, and has been obtained from the ICRISAT (International Crops Research Institute for the Semi Arid Tropics) VDSA (Village Dynamics in South Asia) Apportioned Meso database. This is a district level database. Districts in this database are according to 1966 base, data on districts formed after 1966 is given 'back' to the parent districts i.e. apportioned, based on percentage area of parent district transferred to the new district. Out of the 311 districts, 249 districts were formed after 1966, for which data was apportioned. Hence, the final database comprises of data for districts according to 1966 boundaries.

The variables of interest in this database include area and production of rice (measured in hectares and tons respectively), district-wise consumption of fertilizers (tons of nitrogen, phosphate and potash fertilizers used), total gross cropped area in each district (measured in hectares, and accounting for multiple cropping) area under HYV seeds for each crop (measured in hectares, again accounting for multiple cropping).

In this study the dependent variable is yield (tons of output per hectare). Owing to non availability of crop specific data on fertilizers used, annual aggregate fertilizer consumption is weighted by proportion of gross cropped area devoted to each crop. The resulting variable is further divided by crop area (tons of fertilizers used per hectare). Crop specific irrigated area and area under HYV seeds (tons) are divided by area under the crop and thus measure 
the proportion of crop area irrigated and under HYV seeds, respectively. Summary statistcs of the variables of interest are reported in Table A1. Among inputs, a rising trend in crop yields, irrigated area and fertiliser consumption can be seen in Figures A1-A3.

\section{Climate data}

Climate data has been procured from India Water Portal domain, which uses the publicly available Climate Research Unit (CRU) TS2.1 dataset (Tyndall Centre for Climate Change Research, School of Environmental Sciences, University of East Anglia, Norwich, UK).

The database consists of interpolated (on 0.5 degree latitude-longitude grid) global monthly data on variables such as rainfall and temperature from 1901 to 2002. The CRU data was transformed to the district level by simple linear averaging from the gridded data of the CRU dataset.

The climate variables used for this study from this dataset are rainfall and temperature.

\section{Methodology:-}

The number of districts selected for each of the crops is 162 , which account for around 95 percent of output.

The specification of the stochastic production function is :

$y=f(X, \beta)+\mu=f(X, \beta)+h(X, \alpha) \varepsilon$

where $y$ is measure of output, $X$ is the input vector, $f($.$) is the production function relating X$ to output with $\beta$ being the vector of estimable parameters, $h(X, \alpha)$ is the risk (variance) function, such that $h^{2}$ is the yield variance; $\varepsilon$ is random shock distributed with mean zero and unitary variance, $\alpha$ is the vector of estimable parameters associated with the risk function (where $\alpha>0$ implies that yield variance increases as $\mathrm{X}$ increases, and vice versa).Just and Pope (1978) also show that the above specification satisfies the postulates regardless of specification of $\mathrm{f}($.$) .$

Most empirical studies have used the method of Feasible Generalized Least Squares (FGLS). Alternatively, Maximum Likelihood Estimation (MLE) can be used. However, FGLS estimation is employed in most empirical studies, although MLE is more efficient and unbiased than FGLS for small samples (Saha et al. 1997). Given the large sample size here, FGLS was used, as described in Judge et al. (1988), to estimate a form of fixed effects panel model. The exact procedure is mentioned below (Just and Pope 1978, Cabas et al. 2010).

First stage entails regressing y on $f(X, \beta)$ which gives the least squares residuals, $\hat{\mu}$ which $\quad(\hat{\mu}=y-f(X, \hat{\beta}))$, is a consistent estimator of $\mu$. The second stage uses least square residuals from the first stage to estimate marginal effects of explanatory variables on the variance of production $(\alpha)$. In the second stage, $\ln \hat{\mu}^{2}$ is regressed on its asymptotic expectation $\mathrm{h}(\mathrm{X}, \alpha)$ with $\mathrm{h}($.$\left.) assumed to be an exponential function(i. e. \mathrm{h}=\mathrm{e}^{\mathrm{x}_{\mathrm{i}}^{\prime} \alpha}\right)$. The third and final stage uses predicted error terms from the second stage as weights for generating FGLS estimates for the mean yield equation. The resulting estimator of $\beta$ in this final step is consistent and asymptotically efficient under a broad range of conditions and the whole procedure corrects for the heteroscedastic disturbance term (Just and Pope 1978, 1979).

\section{Estimation}

One expects input usage to be correlated with district specific time invariant attributes, such as land quality, farming techniques and sowing patterns, which makes the fixed effects model suitable for a district level panel study.

Two regressions were run for each crop, explaining mean yield and yield variability. To capture the asymmetry in yield response to climate extremes (Gadgil and Kumar 2006) for each of the climate variables, anomaly variables for both extremes have been included as regressors in the yield variability equation.

Regression equations estimated for the two crops are :

Mean Yield ${ }_{\text {it }}=\beta_{1}+\alpha_{\mathrm{i}}+\delta_{\mathrm{t}}+\beta_{2}$ Rainfall $_{\mathrm{it}}+\beta_{3}$ Temperature $+\beta_{4}$ Fertiliser $_{\mathrm{it}}+$

$\beta_{5}$ Irrigation $_{\text {it }}+\beta_{6} \mathrm{HYV}_{\mathrm{it}}+v_{\mathrm{it}}$

Yield Variance $_{\mathrm{it}}=\beta_{1}+\alpha_{\mathrm{i}}+\delta_{\mathrm{t}}+\beta_{2}$ Rainfall $_{\mathrm{it}}+\beta_{3}$ Temperature $_{\mathrm{it}}+\varepsilon_{\mathrm{it}}$ 
where $\mathrm{i}$ refers to the district and $\mathrm{t}$ refers to the year; $\alpha_{\mathrm{i}}$ denotes district level fixed effects; $\delta_{\mathrm{t}}$ denotes year fixed effects; Irrigation $_{\mathrm{it}}$ is the proportion of gross cropped area (under that crop) which is irrigated; Fertiliser ${ }_{\mathrm{it}}$ is the total amount of fertilisers (nitrogen, phosphate and potash) used; $\mathrm{HYV}_{\mathrm{it}}$ is the proportion of gross cropped area (under that crop) under HYV seeds; Rainfall ${ }_{\text {it }}$ is the annual rainfall; Temperature ${ }_{i t}$ is the average temperature; $v_{i t}$ and $\varepsilon_{i t}$ are stochastic error terms where $\varepsilon_{\mathrm{it}} \sim \mathrm{N}(0,1)$.

\section{Results:-}

Results using weather variables are reported in Table 1 below. Coefficients of district and year fixed effects have been suppressed.

Separate regressions were performed for mean yield and yield variance. Coefficients for mean yield are those obtained in third stage of the three step FGLS procedure, whereas second stage coefficients are the ones reported for yield variance. The explanatory variables for mean yield regression are: proportion of gross cropped area irrigated, proportion of gross cropped area under HYV seeds, crop specific fertilizers used, annual rainfall and annual average temperature, whereas climate extremes, captured using climate anomalies explain crop yield variability significantly. A positive (negative) coefficient in the mean yield regression can be interpreted as a marginal increase in input increasing (decreasing) crop yields, on an average. A positive (negative) coefficient in yield variance regression can be interpreted as higher deviation of rainfall and temperature from the long period average increasing (decreasing) crop yield variability.

\section{Rice}

Coefficients of the irrigation, fertilizer and HYV variable are positive and highly significant, even at 1 percent level of significance. An extra tonne of fertiliser applied (per unit gross cropped area) increases yield, on an average by 5 $\mathrm{kg} / \mathrm{ha}$. Similarly, irrigation expansion and use of HYV seeds increases yields, with a unit increase in irrigated area (as a proportion of gross cropped area) yielding an additional $1207 \mathrm{~kg} / \mathrm{ha}$, whereas the corresponding estimate for HYV use is $571 \mathrm{~kg} / \mathrm{ha}$. Coefficient of rainfall is positive and significant. Higher rainfall increases rice yields, with an additional $100 \mathrm{~mm}$ of rainfall increasing yields by $15 \mathrm{~kg} / \mathrm{ha}$. However, coefficient of temperature is positive and significant at 10 percent level of significance, with a $1^{\circ} \mathrm{C}$ temperature increase increasing rice yields, on an average by $18 \mathrm{~kg} / \mathrm{ha}$.

For the yield variability regression, increases in temperature are found to increase yield variability, with a degree Celsius increase in temperature increasing yield variability by 20 percent. Coefficient of rainfall is positive , indicating that an additional $100 \mathrm{~mm}$ increase in rainfall will reduce rice yield variability by 1 percent.

Table 1:-Fixed effects results using weather variables

\begin{tabular}{|l|l|}
\hline Mean Yield & Rice \\
\hline Rainfall & $0.00015^{* * *}$ \\
& $(1.41 \mathrm{E}-05)$ \\
\hline Meantmp & $0.018^{*}$ \\
& $(0.008)$ \\
\hline Fertiliser & $0.004685^{* * *}$ \\
& $(2 \mathrm{E}-04)$ \\
\hline Irrigation & $1.207 * * *$ \\
& $(0.087)$ \\
\hline HYV & $0.57106^{* * *}$ \\
\hline $\mathrm{R}^{2}$ & $(0.049)$ \\
\hline
\end{tabular}

\begin{tabular}{|l|l|}
\hline Yield Variance & Rice \\
\hline Temperature & $0.204^{* *}$ \\
& $(0.078)$ \\
\hline Rainfall & -0.0001 \\
& $(0.0001)$ \\
\hline $\mathrm{R}^{2}$ & 0.16 \\
\hline
\end{tabular}




\section{Concluding Remarks}

Using a district level panel dataset for India on production of rice for the time period 1966-1999, I estimate the impact of weather variables on mean and variance of crop yields in India using the Stochastic Production Function approach formulated by Just and Pope. I find that increases in temperature increase rice yield variability significantly. Higher rainfall reduces rice yield variability. This is expected since rice is sensitive to fluctuations in rainfall.

Given that agriculture is a major source of livelihood for farmers in India, increasing yield variability will have serious consequences for our economy. Given that agriculture is the main stay of our economy, higher yield variability directly affects farmer incomes. Higher variability in yields increases variability in farm incomes, which is crucial since agricultural income is the farmer's only source of income. Increases in rainfall can help reduce the adverse effects of higher temperature on this sector. Hence, it is imperative to undertake suitable policies to mitigate climate change impacts on this sector to the maximum possible extent.

\section{References:-}

1. Auffhammer, Maximilian, V. Ramanathan, and Jeffrey R. Vincent. 2006. "Integrated model shows that atmospheric brown clouds and greenhouse gases have reduced rice harvests in India." Proceedings of the National Academy of Sciences (PNAS), 103(52): 19668-19672(December 26).

2. Auffhammer, Maximilian, V. Ramanathan, and Jeffrey R. Vincent. 2012. "Climate change, the monsoon, and rice yields in India." Climatic Change, 111: 411-424.

3. Bagla, Pallava. 2012. "Drawing a bead on India's enigmatic monsoon." Science, 335(6071): 910, 24 February.

4. Barah, B.C. 2005. "Dynamic of rice economy in India: emerging scenario and policy options." Occasional Paper 47.

5. Barnabas, B., K. Jager, and A. Feher. 2008. "The effect of drought and heat stress on reproductive processes in cereals." Plant Cell Environment, 31: 11-38.

6. Barnwal, Prabhat, and Koji Kotani. 2010. "Impact of variation in climatic factors on crop yield: A case of rice crop in Andhra Pradesh, India." Economics and Management series, 17: 1-46.

7. Boubacar, Inoussa. 2012. "The effects of drought on crop yields and yield variability: an economic assessment." International Journal of Economics and Finance, 4(12): 51-60.

8. Cabas, Juan, Alfons Weersink, and Edward Olale. 2010. "Crop yield response to economic, site and climatic variables." Climatic Change, 101: 599-616.

9. Dash, Sushil Kumar et al. 2007. "Some evidence of climate change in twentieth century India." Climatic Change.

10. Deschênes, Olivier, and Michael Greenstone. 2007. "The economic impacts of climate change: evidence from agricultural output and random fluctuations in weather." American Economic Review, 97(1): 354-385.

11. Dinar, Ariel et al.,1998. "Measuring the impact of climate change on Indian agriculture." Technical Paper 402, World Bank, Washington, D.C.

12. Edeh, H.O., E.C. Eboh and B.N. Mbam. 2011. "Analysis of environmental risk factors affecting rice farming in Ebonyi state, Southeastern Nigeria." World Journal of Agricultural Sciences, 7(1): 100-103.

13. Food and Agriculture Organization (FAO). 2013. A regional rice strategy for sustainable food security in Asia and the Pacific.

14. Fishman, Ram Mukul. 2012. "Climate change, rainfall variability, and adaptation through irrigation: Evidence from Indian agriculture." Columbia University. January.

15. Gadgil, Sulochana and K. Rupa Kumar 2006. The Asian Monsoon, Agriculture and Economy. In: Wang B (Ed.) Asian Monsoon, Springer.

16. Goswami, B.N. et al. 2006. "Increasing trend of extreme rain events over India in a warming environment." Science, 314: 1442-1445.

17. Government of India (GoI). 2010. "Climate change and India: a 4 x 4 assessment-asectoral and regional analysis for 2030s." Indian Network for Climate ChangeAssessment (INCCA), Ministry of Environment and Forests. November.

18. Government of India (GoI). 2011. Census of India.

19. Government of India (GoI). 2013. "Press note on poverty estimates, 2011-12." Planning

20. Commission. August.

21. Government of India (GoI). 2014. Rice in India : A status paper.

22. Guiteras, Raymond. 2009. "The impact of climate change on Indian agriculture." Mimeo.

23. University of Maryland, College Park. October. 
24. Hasanthika, W.K.A.M.A., J.C. Edirisinghe and R.D.D.P. Rajapakshe. 2013. "Climate variability, risk and paddy production." Journal of Environmental Professionals Sri Lanka, 2(2): 57-65.

25. Holst, Rainer, Yu Xiaohua and Grün Carola. 2011: "Climate Change, Risk

26. and Grain Production in China." Discussion Paper No. 68, Courant Research Centre: Poverty, Equity and Growth.

27. Hossain, M., and K.S. Fischer. 1995. "Rice research for food security and sustainable agricultural development in Asia: Achievements and challenges." Geo Journal, 35: 286-298.

28. ICAR (Indian Council of Agricultural Research). 2008. Crop calendar of major crops. Crop Science Division, Indian Council of Agricultural Research, New Delhi. http://eands.dacnet.nic.in/At_Glance_2008/28Appendix\%201V.xls (accessed on August 12, 2013)

29. ICRISAT Village Dynamics in South Asia (VDSA). "Macro-Meso Apportioned Database".

30. http://www.icrisat.org/vdsa/vdsa-database.htm (accessed on August 10, 2013).

31. IPCC. 2007. IPCC Fourth Assessment Report. The Physical Science Basis, 580.

32. IPCC 2014. Report on Asia, Working Group II, Cambridge University Press, 1327-1370.

33. Just, Richard E., and Rulon D. Pope. 1978. "Stochastic specification of production functions and economic implications." Journal of Econometrics, 7: 67-86.

34. Just, Richard E., and Rulon D. Pope. 1979. "Production function estimation and related risk considerations." American Journal of Agricultural Economics, 61(2): 276-284.

35. Kothawale, D.R., A.A. Munot, and K. Krishna Kumar. 2010. "Surface air temperature variability over India during 1901-2007, and its association with ENSO." Climate Research, 42: 89-104.

36. Krishnamurthy, Chandra Kiran B. 2012. "The distributional impacts of climate change on

37. Indian agriculture: a quantile regression approach." Madras School of Economics Working

38. Paper 69/2012 (May).

39. Kumar, Hemanshu, and Rohini Somanathan. 2009. "Mapping Indian districts across census

40. years, 1971-2001." Centre for Development Economics (Department of Economics, Delhi

41. School of Economics) Working Paper No. 176 (April).

42. Kumar, K.S. Kavi, and Jyoti Parikh. 2001. "Indian agriculture and climate sensitivity." Global Environmental Change, 11(2): 147-154.

43. Kumar, Ajay, Pritee Sharma and Sunil Kumar Ambrammal. 2014. "Climatic effects on food grain productivity in India: a crop wise analysis." Journal of Studies in Dynamics and Change, 1(1): 38-48.

44. Kumar, Ajay, Pritee Sharma and Sunil Kumar Ambrammal. 2015. "Climatic effects on sugarcane productivity in India: a stochastic production function approach." International Journal of Economics and Business Research, 10(2).

45. Lobell et al. 2008. "Prioritizing climate change adaptation needs for food security in 2030." Science, 319 (5863): 607-610.

46. Millet Network of India (MNI), Deccan Development Society and FIAN (Food First Information and Action Network), India. 2009. Millets: future of food and farming.

47. Pandey, S., H. Bhandari, H. and B. Hardy, B. 2007. "Economic costs of drought and rice farmers coping mechanisms: a cross-country comparative analysis," International Rice Research Institute, Manila.

48. May, W. 2004: "Simulation of the variability and extremes of daily rainfall during the Indian summer monsoon and future times in a global time-slice experiment." Climate Dynamics, 22: 183-204.

49. Mc Carl, Bruce A., Xavier Villavicencio, and Ximing Wu. 2008. "Climate change and future analysis: is stationarity dying?" American Journal of Agricultural Economics, 90(5): 1241-1247.

50. Pattanaik, D. R. 2007. "Analysis of rainfall over different homogeneous regions of India in relation to variability in westward movement frequency of monsoon depressions." Natural Hazards, 40(3): 635-646.

51. Poudel, Santosh, and Koji Kotani. 2013. "Climatic impacts on crop yield and its variability in Nepal: do they vary across seasons and altitudes." Climatic Change, 116: 327-355.

52. Ramanathan et al. 2005. "Atmospheric brown clouds: Impacts on South Asian climate and hydrological cycle." Proceedings of the National Academy of Sciences, 102(15): 5326-5333.

53. Ramesh, K.V. and P. Goswami. 2007. "Reduction in temporal and spatial extent of the Indian summer monsoon." Geophysical Research Letters, 34: 1-6.

54. Saha, Atanu, Arthur Havenner, and Hovav Talpaz. 1997. "Stochastic production function estimation: small sample properties of ML versus FGLS.” Applied Economics, 29(4): 459-469.

55. Saini, H. S., and M. E. Westgate. 2000. "Reproductive development in grain crops during drought." Advances in Agronomy, 68: 59-96. 
56. Sanghi, Apurva, and Robert Mendelsohn. 2008. "The impacts of global warming on farmers in Brazil and India." Global Environmental Change, 18(4): 655-665.

57. Sarker, Md. Abdur Rashid, Khorshed Alam, and Jeff Gow. 2014. "A comparison of the effects of climate change on Aus, Aman and Boro rice yields in Bangladesh : evidence from panel data." Economic Analysis and Policy, 44(4): 405-416.

58. Singh, Madan Pal. 2009. "Rice productivity in India under variable climates." Paper presented at MARCO (Monsoon Asia Agro-Environmental Research Consortium) Symposium, October 6-9, Tsukuba, Japan. Workshop 2 (October 6).

59. Wassman, R. 2009. "Climate change affecting rice production: the physiological and agronomic basis for possible adaptation strategies." Advances in Agronomy, 101: 60-110.

60. Yoshida, S., T. Satake, and D. Mackill 1981. "High temperature Stress." International Rice Research Institute Paper No. 67: 1-15.

\section{Appendix 1. Data}

Table A1. Summary Statistics

\begin{tabular}{|l|l|l|l|l|l|}
\hline Variable/Crop & \multirow{2}{*}{ Unit } & Rice & \multicolumn{4}{l|}{} \\
\cline { 4 - 6 } & & Mean & Std. dev. & Min & Max \\
\hline Rainfall & $\mathrm{mm}$ & 1270 & 707 & 117 & 5541 \\
\hline Temperature & ${ }^{\circ} \mathrm{C}$ & 25.66 & 1.46 & 21.18 & 29.61 \\
\hline Area & 000 hectares & 223.51 & 166.69 & 0.00 & 1125.70 \\
\hline Production & 000 tons & 372.89 & 333.96 & 0.00 & 2947.41 \\
\hline Fertiliser Use & tons/hectare & 0.08 & 0.07 & 0.00 & 0.41 \\
\hline Irrigation & proportion & 0.55 & 0.38 & 0.00 & 1.00 \\
& & & & & \\
\hline HYV & proportion & 0.46 & 0.35 & 0.00 & 1.00 \\
\hline Yield (Production/area) & tons/hectare & 1.78 & 0.92 & 0.00 & 21.47 \\
& & & & & \\
\hline
\end{tabular}

Figure A1:-Crop Yield (tons/hectare)

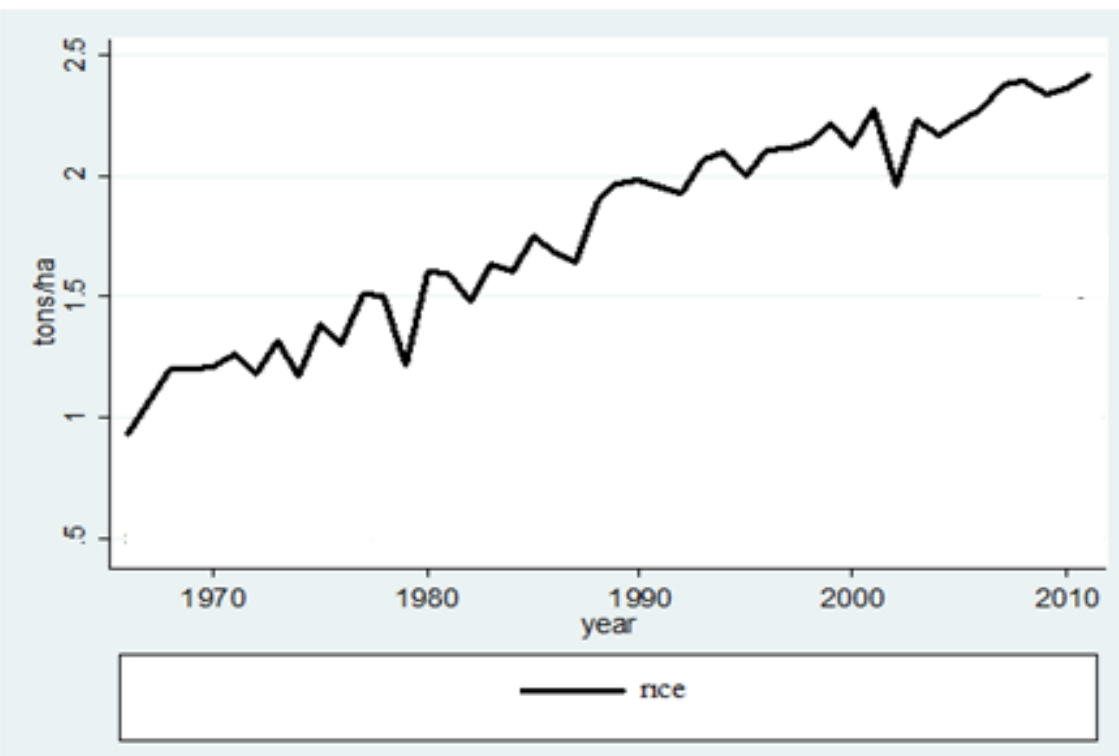


Figure A2:-Irrigated area as a proportion of gross cropped area

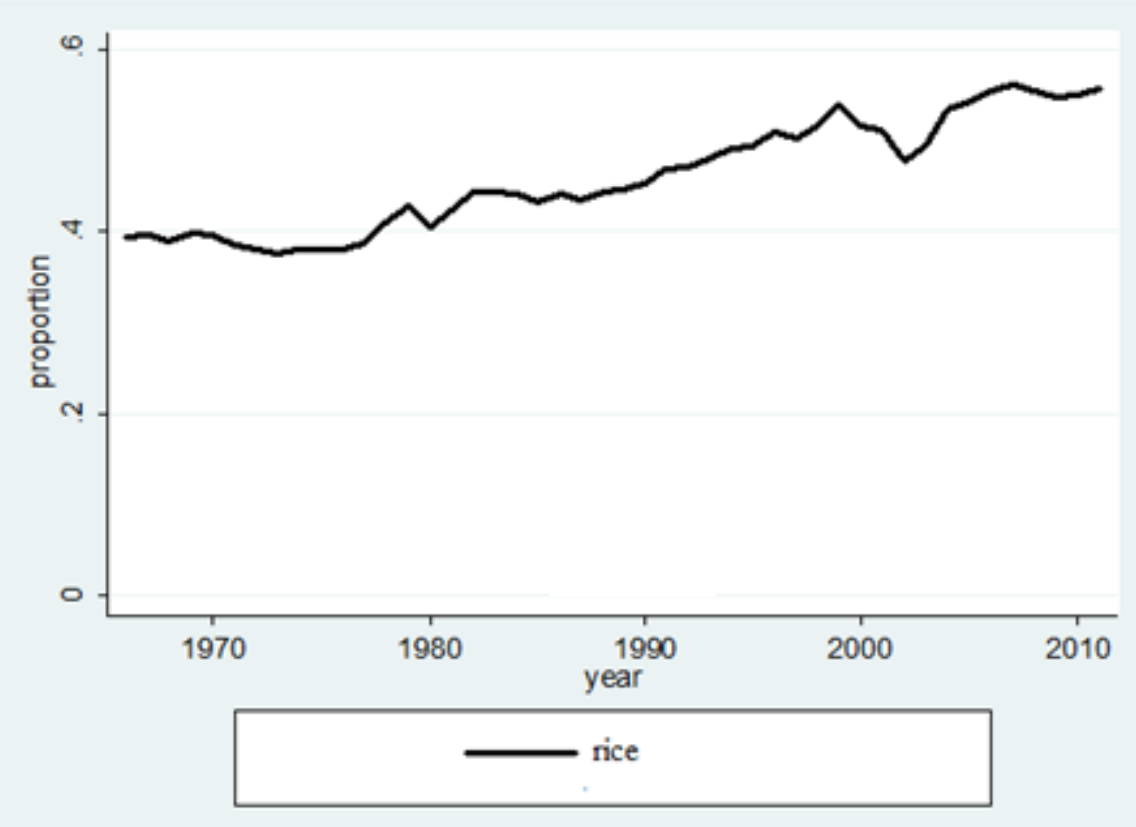

Figure A3:-Fertilizer Use (tons/hectare)

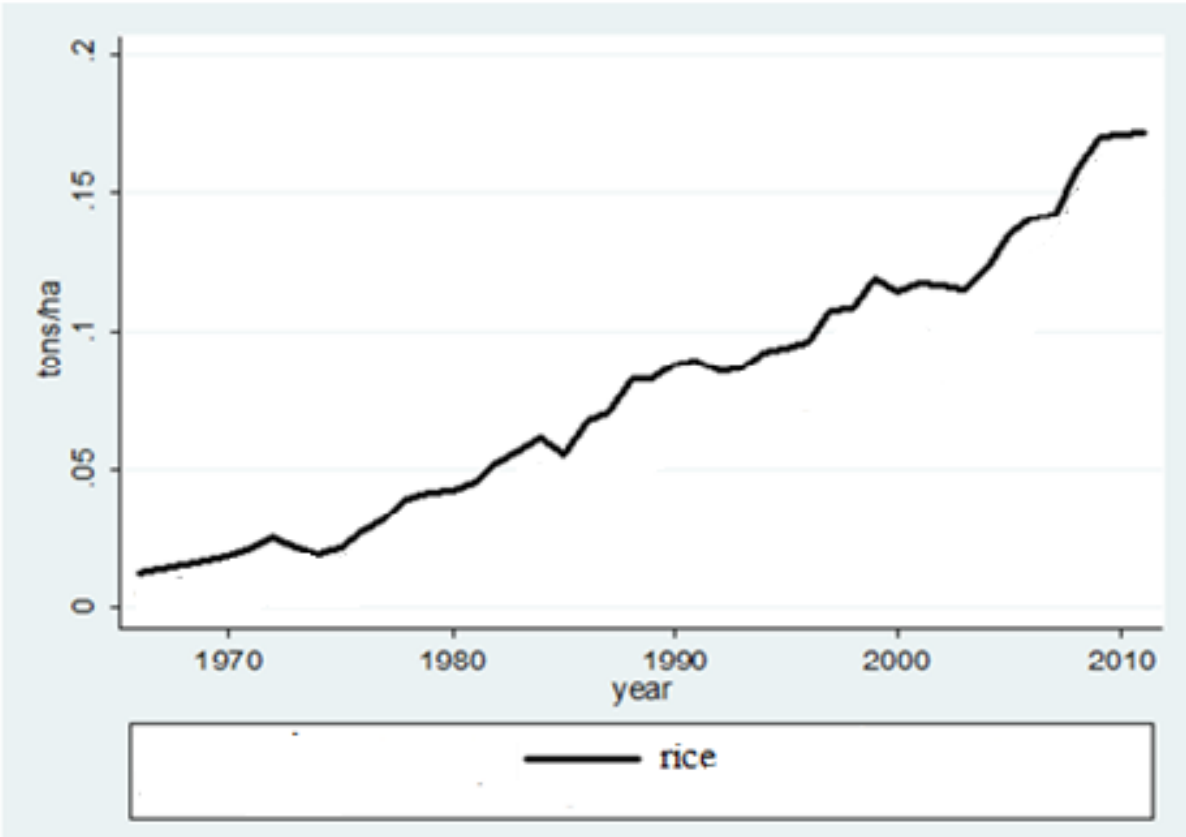

